Vieira da Cunha, Neiva; Feltran, Gabriel de Santis (orgs.) (2013), Sobre periferia. Novos conflitos no Brasil contemporâneo

\title{
Susana Durão
}

\section{OpenEdition}

\section{Journals}

Edição electrónica

URL: http://journals.openedition.org/rccs/5856

DOI: $10.4000 /$ rccs. 5856

ISSN: 2182-7435

Editora

Centro de Estudos Sociais da Universidade de Coimbra

\section{Edição impressa}

Data de publição: 1 dezembro 2014

Paginação: 192-194

ISSN: 0254-1106

\section{Refêrencia eletrónica}

Susana Durão, «Vieira da Cunha, Neiva; Feltran, Gabriel de Santis (orgs.) (2013), Sobre periferia. Novos conflitos no Brasil contemporâneo », Revista Crítica de Ciências Sociais [Online], 105 | 2014, posto online no dia 05 dezembro 2014, consultado o 22 setembro 2020. URL : http://journals.openedition.org/rccs/ 5856 ; DOI : https://doi.org/10.4000/rccs.5856 


\section{Recensões}

\section{Malheiros, Jorge Macaísta; Esteves, Alina (coords.) (2013), Diagnóstico da população imigrante em Portugal. Desafios e potencialidades. Lisboa: Alto Comissariado para a Imigração e Diálogo Intercultural, 324 pp.}

Nas últimas décadas, uma das mais relevantes transformações pelas quais passou a sociedade portuguesa foi a alteração do regime migratório, que a caracterizou desde sempre como país de emigração. De facto, até meados da década de 1970 o país foi marcado pelas saídas de população, tendo a imigração uma expressão residual no contexto demográfico do país. No entanto, a partir de então, verificou-se um crescimento gradual da população estrangeira em Portugal. Os ritmos desse crescimento serão determinados por razões várias, sendo de destacar a adesão à Comunidade Europeia, os sucessivos reajustamentos económicos e setoriais resultantes dessa adesão, bem como tendências conjunturais internacionais. Depois de sucessivos fluxos predominantemente originários do sistema migratório lusófono, no final dos anos 90 ocorreu uma alteração significativa no perfil dos imigrantes, passando estes a ser maioritariamente provenientes de países do Leste europeu, o que contribuiu para que no início do século XXI, a nacionalidade ucraniana surgisse como a mais numerosa entre a população imigrante em Portugal. Posteriormente, em virtude da retração económica e do aumento do desemprego, verificou-se uma progressiva diminuição das entradas. Contudo, em 2009 foi atingido o valor máximo de imigrantes, num total de 454191.

Numa altura em que os fluxos imigratórios decresceram, que o stock de imigrantes tende a estabilizar e em que o contexto nacional é marcado pela recessão económica, por elevadas taxas de desemprego e pelo significativo empobrecimento social, importa perceber qual a situação da população estrangeira no país. A obra em causa, Diagnóstico da população imigrante em Portugal. Desafios e potencialidades, estudo coordenado por Jorge Macaísta Malheiros e Alina Esteves, promovido pelo Alto Comissariado para a Imigração e Diálogo Intercultural, publicado em junho de 2013, proporciona um retrato amplo das condições sociais de permanência da população imigrante de origem não comunitária no país.

O diagnóstico que é feito da população imigrante é de cariz quantitativo, tendo resultado da aplicação de 5669 questionários a imigrantes não comunitários, entre outubro de 2009 e março de 2010, com incidência em 18 concelhos, através de uma amostragem que cobriu todas as regiões portuguesas. O estudo está estruturado por capítulos, sendo que nos primeiros se fazem algumas considerações contextuais e metodológicas, seguindo-se depois capítulos que analisam várias dimensões da presença imigrante.

No capítulo relativo à caraterização demográfica e social das famílias migrantes procede-se a um mapeamento da distribuição geográfica dos inquiridos, sua naturalidade e nacionalidade, bem como à análise dos agregados familiares e do impacto que representam para o contexto da sociedade portuguesa. O capítulo dedicado ao mercado de trabalho identifica o padrão geral 
da condição migrante perante as atividades económicas, a situação na profissão, regimes de trabalho, vínculos contratuais, ocupação e mobilidade profissional. No capítulo relativo à habitação caraterizam-se os alojamentos e condições de habitabilidade. O capítulo sobre as práticas culturais analisa a diversidade religiosa e linguística enquanto expressões culturais associadas à presença imigrante no país, identificando uma dicotomia de práticas a variar entre a preservação de identidades culturais e o cosmopolitismo. $\mathrm{O}$ capítulo dedicado às dificuldades, fatores e níveis de integração dos imigrantes afere o grau de dificuldade experienciado em relação a vários domínios, identificando as condições socioinstitucionais que favoreceram o seu processo de integração, mostrando o perfil das redes sociais de integração e avaliando o nível de integração imigrante no país. O capítulo seguinte aborda a perceção sobre a situação de discriminação em Portugal, dimensionando o grau de discriminação sentido pelos imigrantes, identifica o número de imigrantes que afirmam ter sido vítimas de discriminação, bem como as situações em que as discriminações são mais frequentes. O penúltimo capítulo é dedicado às redes de solidariedade e apoio, analisando-se as sociabilidades informais, o associativismo e direitos de cidadania, as relações institucionais com os serviços de apoio. O último capítulo aborda as práticas transnacionais da relação com os países de origem, nomeadamente ao nível das remessas financeiras, do contacto com as famílias, o reagrupamento familiar, e a problematização da continuação do ciclo migratório.

De forma breve, o retrato proporcionado por este diagnóstico mostra a forma como os imigrantes expressam níveis significativamente elevados de integração social, o que está relacionado com a inserção laboral, a obtenção de rendimentos, a pertença a redes de sociabilidade e a partilha de mecanismos comunicacionais. A obtenção da nacionalidade portuguesa é desejada pela maioria dos imigrantes como forma de melhoria da qualidade de vida, desde logo como facilitadora no acesso ao trabalho. As opções residenciais são predominantemente marcadas pelo arrendamento formal, havendo variações em função das áreas geográficas de destino e do tempo de permanência em Portugal. Os imigrantes revelam algumas vulnerabilidades, nomeadamente o desemprego, a mobilidade profissional descendente, a precariedade dos vínculos contratuais e uma elevada rotação nos empregos. A perceção da discriminação racial e étnica é superior à efetiva experiência de racismo, sendo o local de trabalho o lugar onde a descriminação mais se sente. $\mathrm{O}$ associativismo entre os imigrantes é genericamente baixo. No contacto que os imigrantes mantêm com as instituições portuguesas, a avaliação global é positiva, verificando-se insatisfação relativamente às instituições de controlo e repressão do Estado ou àquelas que desempenham funções burocrático-administrativas. A população imigrante contribui de forma relevante para a diversidade religiosa do país e suas regiões. A maioria dos imigrantes tem a prática regular do envio de remessas para os países de origem, verificando-se contudo uma redução das mesmas em virtude da instabilidade laboral. Entre a população inquirida, $48 \%$ deseja deixar Portugal, seja para regressar ao país de origem, seja para continuar o processo migratório. Importa dizer que o retrato genérico da população imigrante tem nuances e especificidades resultantes das variações de género, estrutura etária, estado civil, naturalidade, nacionalidade, ano de chegada, instrução escolar, situação legal, entre outras variáveis.

Um olhar crítico sobre este estudo detém-se sobre as questões metodológicas. 
Desde logo um aspeto que é genérico aos estudos das migrações consiste na inserção dos imigrantes irregulares nas amostras, facto que pode colocar em causa a representatividade das mesmas, para mais quando se pretende fazer um diagnóstico da população imigrante, independentemente do seu estatuto. Os autores identificam este problema e ultrapassam-no através do método de amostragem multietápico e do recurso a informação dos Censos de 2001 sobre a distribuição regional dos imigrantes. No entanto, a representatividade desta estratégia pode ser questionada tendo em conta a mobilidade geográfica desta população e o facto de a amostra ser baseada na área de residência. Contudo, considera-se que o nível de confiança da amostra permite um retrato bastante nítido do fenómeno em causa. Um outro aspeto metodológico relevante prende-se com o facto de a população migrante originária dos países comunitários não ter sido contemplada no estudo. Se por um lado esta opção se aceita tendo em consideração o estatuto jurídico e social destes imigrantes, por outro lado excluem-se imigrantes originários de países como a Roménia, cuja expressão quantitativa e social no contexto da população imigrante em Portugal não podem ser menosprezados.

O Diagnóstico da população imigrante em Portugal constitui um estudo relevante pela amplitude temática que aborda, pelas múltiplas variáveis sociodemográficas que cruza, pelas diversas dimensões do quotidiano da população imigrante que observa e, consequentemente, pelas informações que proporciona. Num contexto de recrudescimento dos fluxos emigratórios, este trabalho revela que, apesar da tendência de decréscimo, a população estrangeira tem uma representatividade de $5,7 \%$ entre os residentes do país, e uma expressão relevante em determinados domínios da sociedade portuguesa. Assim, apesar da crise, este é um tema social que não se diluiu, antes pelo contrário, com o exacerbar da mesma tornou necessário um olhar mais exigente por parte das instituições públicas. Esta é uma realidade que se revela heterogénea e complexa, apresentando desafios ao nível da integração e inserção social, mas que revela simultaneamente potencialidades para a sociedade portuguesa ao nível demográfico, económico e cultural.

Tendo este estudo sido realizado num período em que a crise económica e social ainda não se fazia sentir com a intensidade com que veio a ocorrer, e considerando a fluidez das migrações e a sua rápida mutação em resultado de alterações sociais, os desenvolvimentos dos últimos anos exigem a continuação deste diagnóstico.

Carlos Nolasco

\section{Fonseca, Maria Lucinda; Góis, Pedro; Marques, José Carlos; Peixoto, João (orgs.) (2013), Migrações na Europa e em Portugal. Ensaios de homena- gem a Maria loannis Baganha. Coimbra: CES/Almedina, 255 pp.}

Um livro de ensaios de homenagem é muito mais do que o conjunto das partes que o estruturam. Materializa o que se poderá designar como uma 'memória de afetos'. A obra Migrações na Europa e em Portugal - Ensaios de homenagem a Maria Ioannis Baganha não é exceção. Organizada por quatro autores, pertencentes a instituições académicas distintas, este livro consubstancia-se num sentimento comum - o reconhecimento do papel fulcral de Maria Ioannis Baganha na criação 
e dinamização dos estudos migratórios em Portugal, em franco debate com uma perspetiva internacional.

Pressupondo que "[...] fazer ciência é também saber posicionar-se em relação ao adquirido, ao que as gerações que nos precederam e aquela a que pertencemos fizeram, e contribuir para a construção de uma ciência cumulativa” (p. 28), este livro faz jus ao legado da homenageada, um legado académico mas também de colaboração interinstitucional e interdisciplinar. Daí a pertinência na escolha dos autores, que direta ou indiretamente colaboraram com a homenageada em projetos de investigação, nacionais e internacionais, e/ou que com ela dialogaram - melhor dizendo dirimiram argumentos.

Quem, porventura, contacta pela primeira vez com esta área de pesquisa, pode, na "Nota Introdutória", conhecer, mais aprofundadamente, o processo de construção do percurso académico de Maria Ioannis Baganha, com reflexos não só ao nível da produção de bibliografia de referência, mas também com repercussões na delimitação das políticas migratórias em Portugal.

Tendo como fio condutor o tributo a Maria Ioannis Baganha, Migrações na Europa e em Portugal - Ensaios de homenagem a Maria Ioannis Baganha divide-se em duas partes: "Migrações na Europa" e "Migrações em Portugal".

A primeira parte, composta por três capítulos, começa com uma revisitação de um dos projetos europeus em que a investigadora participou, neste caso como coordenadora responsável - o projeto europeu PEMINT ("The Political Economy in an Integrated Europe"). Nesse capítulo, precisamente intitulado "The Political Economy of Migrants in an Integrated Europe - A Project revisited ten years after", Hans Entzinger não só delimita os objetivos, o modelo de pesquisa, as propostas teóricas e os principais resultados do projeto PEMINT, como também faz uma pequena incursão ao que poderia ser a replicação desse projeto, agora que passaram dez anos da sua pesquisa empírica. Dentro desse âmbito, são considerados os impactos de algumas transformações sociopolíticas (como o alargamento a Leste, o declínio demográfico, a sedimentação de movimentos populares anti-imigração e a emergência de novos países no cenário económico mundial) na opção pelo recrutamento no mercado de trabalho internacional, comunitário e/ou extracomunitário.

Num segundo capítulo, Joaquín Arango, defensor de um modelo sul-europeu da imigração, analisa o que denomina como sendo "a singularidade da experiência imigratória espanhola”, plasmada no facto de, num curto espaço de tempo, se ter verificado um rápido e sustentado crescimento da população imigrante; e de a crise económico-financeira não ter produzido uma mudança significativa nas atitudes sociais relativamente à imigração e na gestão pública das políticas migratórias. Em "The Comparative Study of Integration Policies of European Cities", Rinus Pennix apresenta-nos o que tem sido o seu contributo para os estudos migratórios, uma análise comparativa e crítica das políticas de integração à escala local. Ressalta deste texto a operacionalização do conceito de "integração", o papel das cidades e municípios europeus como entidades governativas na gestão das práticas e políticas de integração e, por essa via, a necessidade de uma análise das diferentes escalas de governação das políticas de integração - escalas supranacional, nacional e local. O contexto nacional enquanto dimensão analítica perde, assim, o seu relevo explicativo, e o eixo local assume um poder heurístico, visível nas potencialidades de uma convergência inter-regional. 
Na segunda parte, intitulada "Migrações em Portugal”, e ao longo de seis capítulos, abordam-se várias linhas temáticas, objeto de análise nos estudos migratórios portugueses no decurso dos últimos anos: associações de origem imigrante, habitação e processos de integração, imigração e inserção laboral, dinâmicas dos fluxos, impactos demográficos e migrações insulares, políticas e práticas de integração. Sugere-se uma leitura atenta para quem se queira inteirar sobre o que se tem produzido a nível nacional, na maioria dos centros de investigação com tradição nesta matéria.

Dentro deste âmbito, e na esteira de projetos de investigação nacionais conduzidos pela autora, Margarida Marques apresenta as associações de origem migrante enquanto instituições sociais, uma vez que funcionam como elementos estruturantes na formação das comunidades migrantes, mas também desempenham um papel estruturador na transformação da sociedade portuguesa, produzindo o que a autora ilustrativamente designa como "o efeito performativo sobre as estruturas sociais".

A equipa do Núcleo MIGRARE (Migrações, Espaços e Sociedades), liderada por Maria Lucinda Fonseca e composta por Alina Esteves, Jorge Malheiros e Jennifer McGarrigle, concentra-se na integração socioterritorial e no acesso ao mercado habitacional, tendo como referência a região do Algarve. Este capítulo aborda uma dimensão pouco explorada nos estudos sobre processos de integração de imigrantes - o acesso à habitação, a qualidade dos alojamentos e a distribuição residencial. A fragmentação social do espaço urbano e os processos de segregação residencial revelam-se, assim, eixos fundamentais nos debates sobre a inclusão das comunidades imigradas.

Por sua vez, João Peixoto, ao abordar uma temática frequentemente retratada nos estudos das migrações - imigração, emprego e mercados de trabalho -, fá-lo a partir de uma perspetiva inovadora, ao correlacionar o modelo de inserção dos migrantes no mercado de trabalho português com uma análise diacrónica da situação económica portuguesa.

Dois investigadores que trabalharam em estreita colaboração com a homenageada - José Carlos Marques e Pedro Góis - reanalisam o conceito de "sistema migratório lusófono", atendendo às novas dinâmicas migratórias para três países que foram colonizados por Portugal Brasil, Moçambique e Angola. Ao apresentarem uma ligação estrutural deste sistema migratório lusófono com outros sistemas migratórios regionais, os autores defendem uma leitura integrada das configurações migratórias, considerando, nomeadamente, momentos de retração e de expansão e a participação, simultânea, em diferentes sistemas migratórios.

Gilberta Pavão Nunes Rocha analisa os impactos demográficos das migrações internacionais numa região, como os Açores, que já tinha sido objeto de cuidado estudo por parte de Maria Ioannis Baganha, quando desenvolveu a sua tese de doutoramento. Neste capítulo, confirma-se o impacto dos contextos internacionais nas dinâmicas migratórias de um espaço insular, como os Açores. Este texto consolida a importância de uma perspetiva demográfica nos estudos sobre a mobilidade internacional.

A terminar, Ana Paula Beja Horta reflete sobre a evolução dos fluxos migratórios, e-/i-migratórios, e as diferentes conceções políticas e práticas de integração: migrações e o acesso à nacionalidade, "Política de Laissez-Faire", o discurso público de integração e a institucionalização da imigração; e o projeto político da interculturalidade. Quem se interessa por uma análise dos discursos institucionais e da evolução 
das políticas de integração, encontrará, neste texto, a possibilidade de um registo orientador.

No cômputo geral, de referir apenas uma pequena lacuna. A ausência de um capítulo final, interlocutor entre as duas partes, "Migrações na Europa" e "Migrações em Portugal”. Compreende-se, no entanto, a opção dos organizadores de não apresentar o livro como uma obra fechada, vinculada a uma única posição heurística, o que certamente não espelharia o pensamento firmado por Maria Ioannis Baganha.
Mais do que uma possível síntese do que, nos últimos quinze anos, se tem consolidado como objeto de análise nos estudos migratórios, em Portugal e em alguns países europeus, este livro de ensaios convida a refletir sobre direções futuras, sobre o trilho de caminhos prováveis; no fundo, convoca-nos para o que poderá ser um dos maiores contributos de Maria Ioannis Baganha para as gerações futuras dos estudos migratórios - a contínua e incessante problematização crítica.

Joana Sousa Ribeiro

\section{Vieira da Cunha, Neiva; Feltran, Gabriel de Santis (orgs.) (2013), Sobre periferia. Novos conflitos no Brasil contemporâneo. Rio de Janeiro: Lamparina/Faperj, $224 \mathrm{pp}$.}

Favela, periferia, margem são, por vezes, sinónimos intercambiáveis da histórica precariedade urbana brasileira. Mas são também nomes defendidos, definidos. O termo favela existe há mais de um século no plano social e na geografia urbana e há mais de duas décadas no domínio da reflexão acadêmica. Continua saindo da sombra.

Sobre periferia. Novos conflitos no Brasil contemporâneo busca desvelar, tal como uma boa camada de obras e de artigos, um dos temas mais promissores de certo estilo de antropologia urbana que vem sendo realizada no Brasil. Não tendo sido o primeiro e nem sendo com certeza o último, o livro reúne nomes que vêm marcando passo nos debates sobre margens urbanas. Após a sua leitura a proposta fica clara: caminhar da reflexão sobre fronteiras sociogeográficas - das periferias - em direção a uma proposta de "cartografia de perspetivas analíticas" - de margens. A obra é composta por três partes diferentes: i) drogas, crime, violência e política; ii) expressividade, religiosidade e gestão social; iii) Estado, território, moradia e ação social.

A discussão inicia-se com as fronteiras dos espaços urbanos do crack, pela mão de Taniele Rui. A autora convence-nos de que diferentes lugares não são meros invólucros e cenários do consumo; diferentes territórios criam parâmetros de interação e novas relações. Três territorialidades distintas no uso do crack, em cidades do estado de São Paulo, apontam contrastes nas tensões que conjugam pessoas, socialidade e cidade, tensões com agentes que ora acolhem, ora punem esses "corpos abjetos”. O espaço do consumo faz diferença, diz Rui. Passamos em seguida à leitura possível do limite (ou "tensão liminar") com uma circulação intermitente de pessoas dentro e fora de albergues na cidade de São Paulo. Aqui, a aparente 'desespecificidade' do público é, paradoxalmente, a especificidade do albergue. Daniel De Lucca Costa sintetiza: esta é uma instituição tão hostil quanto hospitaleira; ela acolhe enquanto expulsa. Diogo Lyra explora o tema da punição entre jovens traficantes, 
conferindo inteligibilidade ao que seria do plano (moral) do ininteligível: a coesão na tensão e na violência. $\mathrm{O}$ caminho é trilhado no nível das palavras trocadas, ajudando o autor a esclarecer uma miríade de noções emic que dão sentido ao que designa como subjetividades do "sujeito-homem". A primeira parte termina com uma cartografia da margem, proposta por Leilah Landim, que ruma através da leitura de organizações civis, elegendo como campo de atuação o tema-problema "violência urbana" no Rio de Janeiro.

"Artes da periferia", por Rose Hikiji e Carolina Caffé, continua evidenciando a proliferação de expressões e de desempenhos culturais que parece oferecer novo contexto a disputas pela representação de lugares e pessoas na margem. O Estado, associações e a gestão começam a ganhar textura analítica por intermédio da análise etnográfica de políticas públicas (Ana Paula Galdeano), mas também já estavam nos espaços urbanos do crack, intersectados por uma pletora de atores institucionais (Taniele Rui). Galdeano descreve, num texto rigoroso e criativo, como a política de segurança pública vai colonizando as políticas de habitação, reforma e lazer em São Paulo na década de 2000. Múltiplos projetos e ativismos que passam pela gestão social da violência, em locais onde se faz presente o Primeiro Comando da Capital (PCC), passam por novas interseções entre polícia, religião e partidos que ora forçam a reintegração da ordem, ora a contestam. A mobilização social e política nas periferias está longe de ser estável. Wania Mesquita apresenta formas de entendimento, compreensão e tolerância moral entre os agentes do crime e os pentecostais, enquanto Nina Rosas, que encerra a segunda parte da obra, sublinha como "uma massa de fiéis empobrecidos" e as obras de assistência social em geral têm sido instrumentalizadas para obtenção de sucesso pessoal e afirmação de carreiras religiosas e partidárias.

A discussão das fronteiras e passagens fica clara no caso dos projetos de "pacificação" policial de favelas, apresentado e discutido por Márcia Leite e Machado da Silva, com novas formas de regulação que facilmente se sobrepõem à lei. A análise tenta explicar o cruzamento entre barreiras mentais invisíveis e a segregação socioterritorial. Os autores sugerem que a contenção e os limites da circulação de jovens favelados na cidade carioca parecem prepará-los para lidar com o desconforto e a insegurança das interações quotidianas urbanas. Tal é feito através de "mapas de antecipação" (conceito tomado de empréstimo de Jeganathan no texto "Checkpoint: Anthropology, Identity, and the State", in V. Das; D. Poole (orgs.), Anthropology in the Margins of the State) que envolvem cartografias dos estigmas e preconceitos. Por eles, polícia e Estado são percebidos através da sua face repressiva, longe do que seria a missão original de provisão de serviços públicos e equipamentos urbanos. Isabel Georges e Yumi dos Santos usam a categoria beckeriana de "emprendedor moral" para descrever políticas sociais terceirizadas de assistência a famílias em São Paulo. Concluem que uma gestão sexuada pode produzir, especialmente nas mulheres assistidas, novas formas de desigualdade. Luciana do Lago vem falar-nos de empreendimentos autogeridos nas periferias de São Paulo e Porto Alegre e das dificuldades manifestas deste tipo de associativismo. A autora demonstra serem poucos os governos locais, as municipalidades, que utilizam instrumentos legais para regular ou reduzir a ação privada que tende a alimentar a especulação fundiária. E por fim, Marluci Menezes e Tânia Ramos apresentam um caso em Lisboa. Descrevem minuciosamente e no tempo a edificação e as transformações 
urbanas no bairro de Chelas. As autoras defendem que a associação representacional frequente entre insegurança e um território específico é (re)criadora de periferia urbana, demarcando-a fatalmente da cidade, mesmo que subvertendo o plano urbanístico-social original.

No seu conjunto, esta é uma dessas coletâneas que resulta do acúmulo de experiências, tanto empíricas quanto conceituais, que têm transformado em objeto de pesquisa antropológica os espaços urbanos e a vida em cidades. Como refere Birman, na abertura do livro, todos os autores da obra recusam o dualismo que oporia centro e periferia. A aposta está na ampliação e não no estreitamento de propostas.

Pela sua complexidade, entender as margens exige diluição de fronteiras estanques e previamente dadas ao observador desavisado. A dicotomia "cidade partida" (proposta no famoso livro de Zuenir
Ventura), que se tornou uma metáfora de uso cognitivo fácil, sobretudo para o caso do Rio de Janeiro, não reúne consistência analítica. Ela é uma performance em si mesma (ainda que possa ter efeitos reais) e só nessa medida requer atenção. Como bem advertem Neiva Vieira da Cunha e Gabriel de Santis Feltran, discutir periferias contemporâneas implica conhecer o labor do tempo no espaço social, o mundo do trabalho, socialidades locais e circulações, configurações públicas de conflitos sociais e políticos emergentes, mas também diferentes sentimentos morais, demandas por respeito, reconhecimento, solidariedade. Que não restem dúvidas depois de ler o livro: periferia é um conceito polissêmico e os territórios da pobreza são amplamente heterogêneos. Mas dizer isto não é dizer tudo. O trabalho teórico começa aqui.

Susana Durão

\section{Carlos Nolasco}

Centro de Estudos Sociais da Universidade de Coimbra

Colégio de S. Jerónimo, Largo D. Dinis, Apartado 3087, 3000-995 Coimbra, Portugal

Contacto: cmsnolasco@ces.uc.pt

\section{Joana Sousa Ribeiro}

Centro de Estudos Sociais da Universidade de Coimbra

Colégio de S. Jerónimo, Largo D. Dinis, Apartado 3087, 3000-995 Coimbra, Portugal

Contacto: joanasribeiro@ces.uc.pt

\section{Susana Durão}

Instituto de Filosofia e Ciências Humanas da Universidade Estadual de Campinas, UNICAMP Rua Cora Coralina, 100, CEP 13083-896 - Cidade Universitária Zeferino Vaz - B. Geraldo

Campinas - São Paulo, Brasil

Contacto: ssbdurao@gmail.com 